\title{
Preparation and Adsorption Properties of Mesoporous Silica for Removal of Nonylphenolethoxylates Surfactant from Aqueous Solution
}

\author{
Sameer H. Kareem and Qutban Ibrahim \\ Department of Chemistry - College of Science- University of Baghdad
}

\begin{abstract}
Mesoporous Silica (MPS) with different ratio silica/surfactant were prepared by sol-gel method based on the hydrolysis and condensation of sodium silicate in the presence of cationic or amphoteric surfactant as template. The silica prepared and their ordered mesostructures were characterized by Fourier transform infrared spectroscopy (FTIR), X-ray diffraction (XRD), atomic force microscopy (AFM), and nitrogen sorption analysis. The result indicate that the preparation of mesoporous silica were successful. The sample of higher surface area was used as adsorbent for the removal of nonylphenol ethoxylates (NPE) surfactant. The adsorption experiments were carried out to measure the adsorption as a function of contact time, adsorbent dose, and temperature in the range (298 - $328 \mathrm{~K}$ ). The adsorption isotherm was constructed and fitted with the Langmuir and Freundlich models. The adsorption kinetic of NPE on MPS matched well with Pseudo-second-order and the values of thermodynamic parameters indicate that the adsorption process was spontaneous and endothermic in nature.
\end{abstract}

Keywords: Mesoporous silica, Sodium silicate, sol-gel method, Nonlphenolethoxylate, Adsorption isotherm

\section{Introduction}

Mesoporous has been adopted by IUPAC to define porous materials with pore sizes between 2 and $50 \mathrm{~nm}[1]$.Ordered mesoporous silica has unique properties, including good monodispersity, with extremely high surface areas, large pore volume, controlled pore size, high mechanical and thermal stability [2]. Therefore, the mesoporous silica have received much attention for their practical applications such as: Drug delivery systems [3], Catalysis [4], Diagnostics [5], Chromatography [6], and Adsorbents [7].

Porous silica was synthesized via the sol-gel method using clay obtained from Nigeria and compared with silica synthesized under similar conditions from sodium metasilicate $\left(\mathrm{Na}_{2} \mathrm{SiO}_{3}\right)$ which was obtained commercially [8]. The analytical results showed that the vibrational modes and diffraction patterns of the silica derived from commercial $\mathrm{Na}_{2} \mathrm{SiO}_{3}$ and that prepared from clay were similar containing pure amorphous $\mathrm{SiO}_{2}$. Hatem M.A. [9] study the effect of a number of previously untested conditions: acid type $\left(\mathrm{HCl}, \mathrm{HNO}_{3}\right.$, and $\left.\mathrm{H}_{2} \mathrm{SO}_{4}\right)$, silica precursor type (Tetrabutylorthosilicate (TBOS) and Tetraethylorthosilicate (TEOS)), and surfactant type (cetyltrimethylammonium bromide CTAB, Tween 20, and Tween 80) on the shape and structure of products formed. TBOS-CTAB-HCl was the typical combination to produce fibers with high order in the interfacial region. The use of other acids $\left(\mathrm{HNO}_{3}\right.$ and $\left.\mathrm{H}_{2} \mathrm{SO}_{4}\right)$, a less hydrophobic silica source (TEOS), and/or a neutral surfactant (Tweens) facilitate diffusion and homogenous supply of silica source into the bulk phase and give spheres and gyroids with low mesoporous order.

Characterization of synthesized and functionalized ordered mesoporous silica was performed and the silica with a large surface area was used to synthesize cobalt nanoparticles [10]. Investigation by SEM and TEM showed hexagonal particles, with a pore size about $10 \mathrm{~nm}$. The functionalization of the silica was studied by FTIR and TG/DTA techniques and the obtained nanoparticles were characterized by XRD, TEM and EDX analysis. A new dual soft-template system [11] comprising the asymmetric triblock copolymer poly (styrene-b-2-vinyl pyridine-bethylene oxide) (PS-b-P2VP-b-PEO) and the cationic surfactant cetyltrimethylammonium bromide (CTAB) is used to synthesize mesoporous silica nanoparticles with a center void of around $17 \mathrm{~nm}$.

Mesoporous SBA-15 bifunctionalized with cetyl and amino groups (cetyl/amino-SBA-15) was successfully prepared by a post-synthesis grafting method [12]. The adsorption capacity of cetyl/amino-SBA-15 was much higher than the arithmetic sum of those of cetyl-SBA-15 and amino-SBA-15 due to the cooperative effect of hydrogen bonding/electrostatic interaction. $\mathrm{CH}_{3}$-functionalized mesoporous silica with nearly spherical morphology was synthesized by co-condensation of two different silica precursors in the presence of triblock copolymer P123 as template [13]. XRD, $\mathrm{N}_{2}$ adsorption-desorption, SEM and ${ }^{29} \mathrm{Si}$ MAS NMR were used to identify its highly-ordered mesopore array structure. It showed the higher adsorption performance when they were used as adsorbents to remove organic pollutant nonylphenol at a very low concentration from aqueous solution. Porous resins as adsorbents for removal of three compounds, phenol, bisphenol A and nonylphenol ethoxylates from aqueous solutions have been evaluated [14]. The adsorption isotherms were well fitted by the Langmuir equation. Adsorption of $\mathrm{NPEO}_{10}$ to polymeric adsorbents was dominated by pore size and molecular morphology, even on the aminated polymeric adsorbents (MN-100, MN-150). The results from thermodynamic analysis show that the adsorption of BPA and $\mathrm{NPEO}_{10}$ by 


\section{International Journal of Science and Research (IJSR) \\ ISSN (Online): 2319-7064 \\ Index Copernicus Value (2013): 6.14 | Impact Factor (2014): 5.611}

polymeric adsorbents was thermodynamically favorable and generally endothermic whereas the adsorption process of phenol was exothermic.

In this work sol-gel method was used to prepare mesoporous silica by using inorganic source of silica sodium silicate and cetyltrimethylammonium bromide (CTAB) and Cocamidopropyl betaine as templates. The mesoporous silica can be used in the adsorption of surfactant due to porous structure and textual properties which allow easier diffusion of a large molecule into active sites, so that, the present work include also the adsorptive properties of the prepared mesoporous silica for removal of nonionic surfactants Nonylphenol ethoxylates (NPE).

\section{Materials and methods}

\subsection{Materials}

Sodium silicate was used as a silica source purchased from local market $\left(14 \% \quad \mathrm{NaOH}, 27 \% \quad \mathrm{SiO}_{2}\right)$. The surfactant cetyltrimethylammonium bromide (CTAB) (99\% SCRCchina), Cocamidopropyl betaine (CAPB) (32\% state company of plant oils - ministry of industry and minerals) were used as template. The acid used is nitric acid $(69 \%$ ACS, Reag) .The adsorbate used is Nonylphenol ethoxylates (NPE) as nonionic surfactants and is a category of alkylphenol ethoxylates $\left(99.7 \%\right.$, molar mass $\left.660 \mathrm{~g} \mathrm{~mol}^{-1}\right)$.

\subsection{Instruments}

There are many techniques have been used in the characterization of the prepared silica and adsorption study; these are as following:

- The IR spectra of silica samples were recorded over the range of $4000-400 \mathrm{~cm}^{-1}$ by means of Fourier Transform Infrared Spectroscopy ( FTIR) , using FTIR spectrometer SHIMADZU.

- The surface area, pore size, and pore volume were determined from nitrogen adsorption - desorption isotherms which were measured at $77 \mathrm{~K}$ using a Micromeritics ASAP2020 V3.04G analyzer (micrometrics, Inc, USA).

- The particle size and particle size distributions were analyzed using Atomic Force Microscopy (AFM) SPMAA 3000, Advanced Angestrum Inc., USA.

- X-ray diffraction (XRD): SHIMADZU (XRD-6000).

- UV-Visible spectrophotometer (SHIMADZU (uv1800)).

\subsection{Synthesis}

Three samples of mesoporous silica were prepared; the first (Z) was synthesized using sodium silicate as silica precursor and $\mathrm{CTAB}$ surfactant as template in the ratio1: 0.5 . The procedure used is [15]: $3.75 \mathrm{~g}$ of cetyltrimethylammonium bromide (CTAB) was dissolve in $150 \mathrm{ml}$ of distilled water, and put in around bottom flask with $34 \mathrm{ml}(1 \mathrm{M}) \mathrm{HNO}_{3}$ with stirring for 1 hour. In $250 \mathrm{ml}$ beaker $7.5 \mathrm{~g}$ of sodium silicate was dissolve in $150 \mathrm{ml}$ of distilled water and was added to the mixture drop by drop from burette for 3 hours. The white precipitate formed spontaneously and then it was recovered by filtration, washed, after aging for one day at $35^{\circ} \mathrm{C}$. The surfactant was removed by calcination at $600^{\circ} \mathrm{C}$ for 4 hours.

The second and third ( $\mathrm{X}$ and $\mathrm{Y}$ ) was synthesized using sodium silicate as silica precursor and CAPB surfactant as template in the ratio 1: 1 and 1:0.5 respectively. The procedure used is modified from that initially developed by Kosuge and other [16]: $7.5 \mathrm{~g}$ of cocamidopropyl betaine was dissolve in $150 \mathrm{ml}$ of distilled water. In another $250 \mathrm{ml}$ beaker $7.5 \mathrm{~g}$ of sodium silicate was dissolve in $150 \mathrm{ml}$ of distilled water and was added to the cocamidopropyl betaine in around bottom flask with stirring for 1 hour. Finally $35 \mathrm{ml}$ of $(1 \mathrm{M}) \mathrm{HNO}_{3}$ was added from burette to the mixture drop wise for 3 hours until the $\mathrm{pH}$ reach to (7). The white precipitate formed spontaneously and then it was recovered by filtration, washed, after aging for one day at $35^{\circ} \mathrm{C}$. The surfactant was removed by calcination at $600^{\circ} \mathrm{C}$ for 4 hours.

\subsection{Adsorption Study}

The sample choices as adsorbent for adsorption study is sample $\mathrm{Z}$ and the adsorbate is NPE surfactant. Adsorption experiments were carried out in $100 \mathrm{ml}$ conical flasks immersed in a thermostatic shaker bath. $0.2 \mathrm{~g}$ of mesoporous silica sample was mixed with $50 \mathrm{ml}$ of the aqueous solutions of various initial concentrations (2-50ppm) of Nonylphenol ethoxylates (NPEs). The flasks with their contents were shaken for different adsorption times at the temperatures $298,308,318$, and 328. At the end of adsorption interval; the supernatant was centrifuged for $10 \mathrm{~min}$. The concentration of NPE in the supernatant solution before and after the adsorption was determined with a $1.0 \mathrm{~cm}$ light path quartz cells using UV-Visible spectrophotometer at maximum wavelength $\left(\lambda_{\max }\right)$ of $218 \mathrm{~nm}$. The amount of adsorbed surfactant at equilibrium $\mathrm{q}_{\mathrm{e}}\left(\mathrm{mg} \cdot \mathrm{g}^{-1}\right)$ was calculated from Equation (1) while the percentage removal was calculated from Equation (2) :

$$
\begin{aligned}
\mathrm{q}_{\mathrm{e}} & =\frac{(C o-C e) \mathrm{V}}{W} \\
\mathrm{R} \% & =\frac{(C o-C e)}{C o} \times 100
\end{aligned}
$$

where, $\mathrm{C}_{\mathrm{o}}$ and $\mathrm{C}_{\mathrm{e}}\left(\mathrm{mg} \mathrm{L}^{-1}\right)$ are the liquid phase concentration of surfactant at initial and equilibrium stages respectively, $\mathrm{V}$ (L) is the volume of the solution and $\mathrm{W}(\mathrm{g})$ is the mass of adsorbent used.

\section{Results and Discussion}

\subsection{Characterization}

The IR spectra of silica samples prepared were recorded and the typical spectra of the sample (z) before and after calcination are depicted in Figs. 1 and 2 .The broad bands at $3491-3626 \mathrm{~cm}^{-1}$ can be assigned to a stretching vibration of the $\mathrm{OH}$ group and to adsorbed water. The strong bands at 1101 and $790 \mathrm{~cm}^{-1}$ can be assigned to an asymmetric stretching vibration of $\mathrm{Si}-\mathrm{O}-\mathrm{Si}[11]$.The band at $968 \mathrm{~cm}^{-1}$ corresponds to $\mathrm{Si}-\mathrm{OH}$ stretching vibrations of the surface silanols. The band at $472 \mathrm{~cm}^{-1}$ is assigned to $\mathrm{Si}-\mathrm{O}-\mathrm{Si}$ vibrations ( $\mathrm{SiO}_{4}$ tetrahedron vibration). The band at 1635 $\mathrm{cm}^{-1}$ is assigned to bending vibration of adsorbed water. The occurrence of absorption bands from the vibrations of the $\mathrm{Si}-\mathrm{O}-\mathrm{Si}, \mathrm{Si}-\mathrm{O}$ bond, and $\mathrm{O}-\mathrm{H}$ bond in the infrared spectrum indicates that the sample must be $\mathrm{SiO}_{2}$. The bands at 2924- 


\section{International Journal of Science and Research (IJSR) \\ ISSN (Online): 2319-7064 \\ Index Copernicus Value (2013): 6.14 | Impact Factor (2014): 5.611}

$2854 \mathrm{~cm}^{-1}$ can be assigned to a stretching vibration of the C$\mathrm{H}$ group. In Figure (2) there is no evidence of bands related to vibration of $\mathrm{C}-\mathrm{H}$, which shows that the organic template in mesoporous silica is eliminated by calcination. Therefore, the composition of the synthesized materials must be $\mathrm{SiO}_{2}$ according to the above-mentioned analysis of the infrared spectrum [17]-[18].

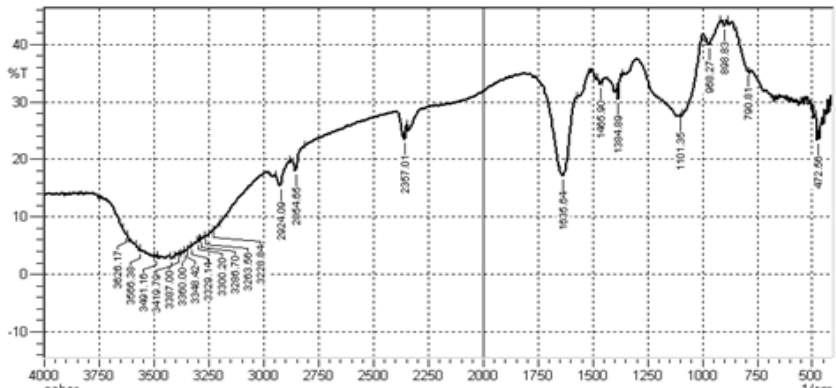

Figure 1: The infrared spectrum of sample (z) before calcinations

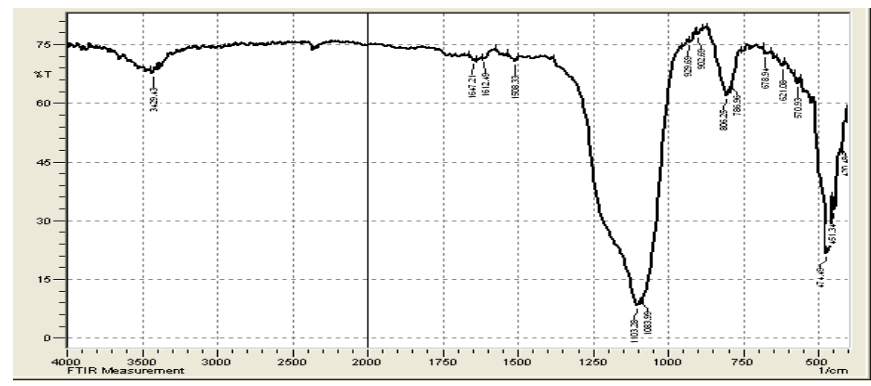

Figure 2: The infrared spectrum of sample $(Z)$ after calcinations

XRD is commonly used to identify the crystallographic symmetry of material phases at both the nano- and mesoscale. X-ray diffraction patterns in the range of 1-10 of synthesized samples X, Y, Z are shown in Figures (3-5) respectively. The products show a single, well-resolved, strong diffraction peak at $2 \theta=1.9005$ for $X$, Y samples and $2 \theta=1.9340$ for $Z$ sample which shows a high degree of ordering of the porous structure. This is attributed to the typical diffraction peak of mesoporous $\mathrm{SiO}_{2}[11]$. Using the related data and Scherer equation $(D=0.9 \lambda / B \cos \theta)$, where $\lambda$ is wavelength of $\mathrm{x}$-ray $(\AA)$, B is FWHM (radian) and $\theta$ is position (radian), the average size of silica particles were calculated and the results show that the size of particles of three samples prepared $X, Y$, and $Z$ are 69,57 , and 33.59 $n m$ respectively.

Figures (6-8) show the roughness of the surface for the samples investigated using atomic force microscopy (AFM). We show that the diameter of the particles are in the ranges 65-110 nm, 45-100nm, 60-110 nm, while the average diameter are $82.18 \mathrm{~nm}, 76.48 \mathrm{~nm}$, and $77.75 \mathrm{~nm}$ for the $\mathrm{X}$, $\mathrm{Y}$, and $\mathrm{Z}$ samples respectively. It is reasonable to assume that a high regularity of the surface objects reflects real surface organization characteristic of MPS particles [19].

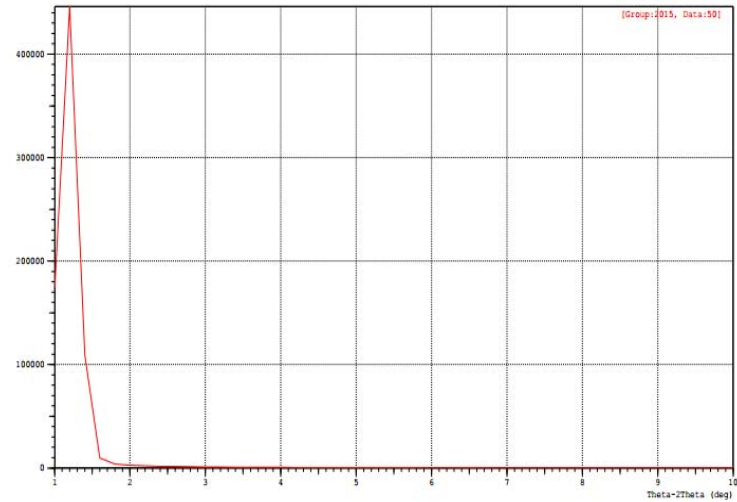

Figure 3: XRD patterns of sample (X).

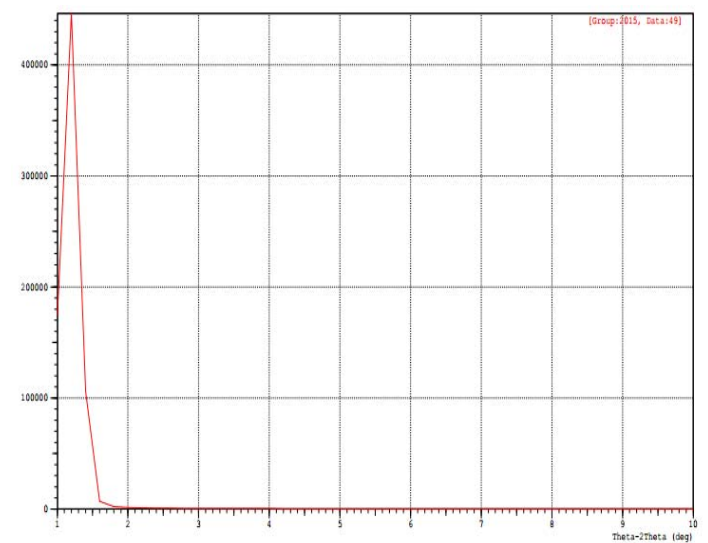

Figure 4: XRD patterns of sample (Y).

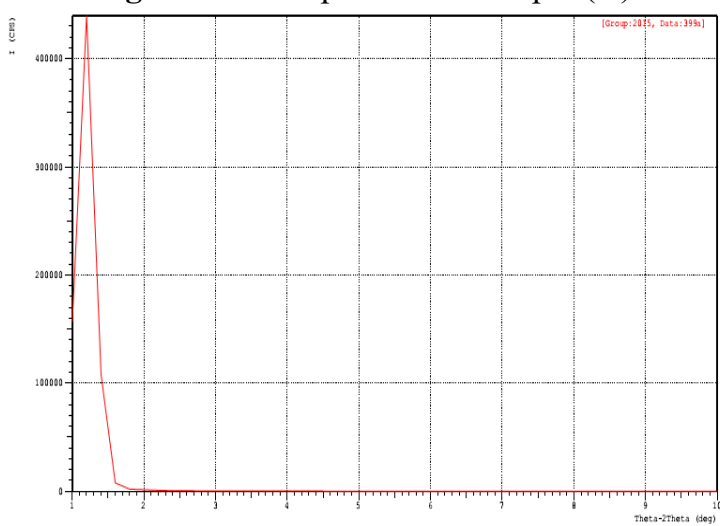

Figure 5: XRD patterns of sample (Z). 

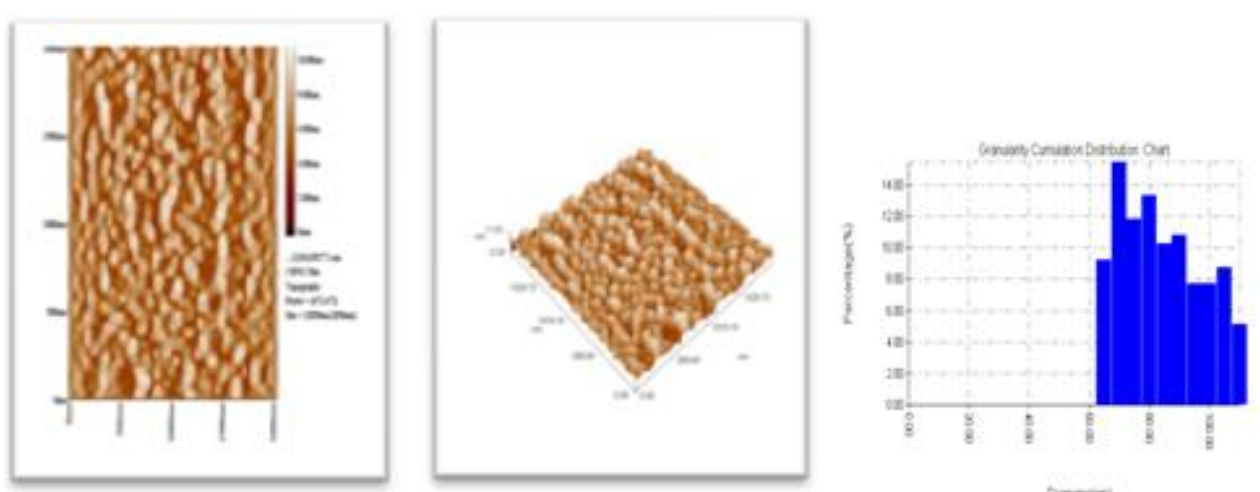

Figure 6: AFM Image of $X$ sample.
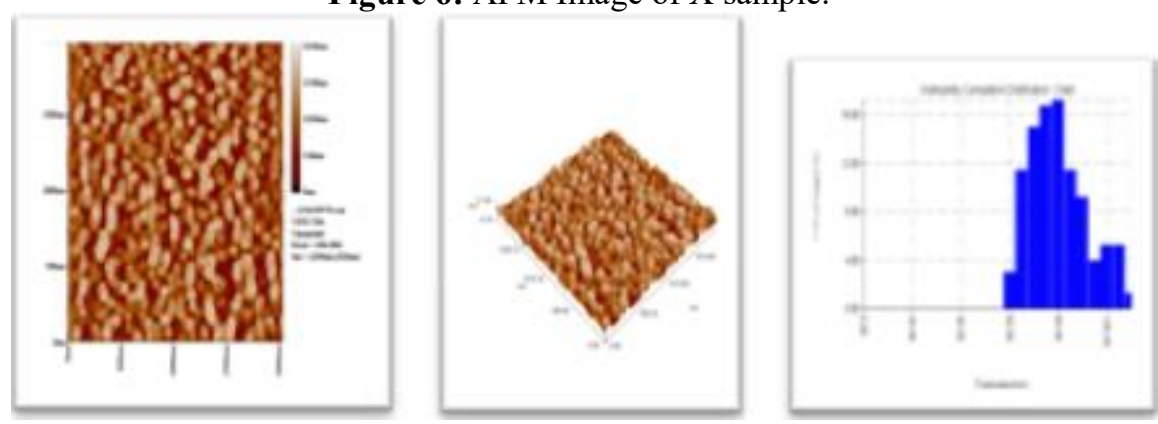

Figure 7: AFM Image of Y sample.
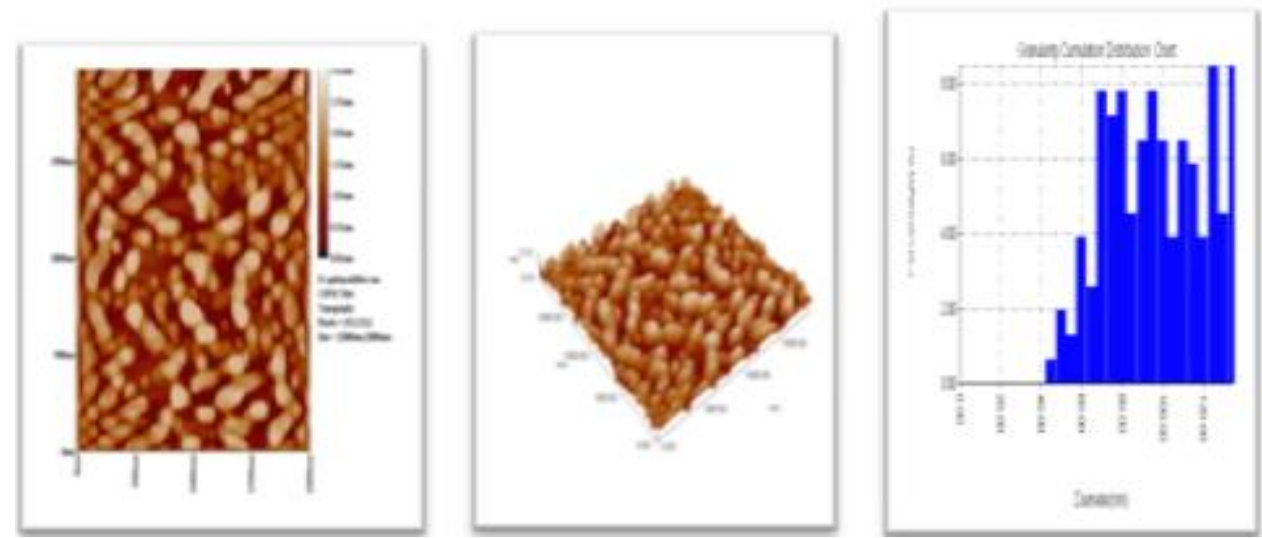

Figure 8: AFM Image of $Z$ sample.

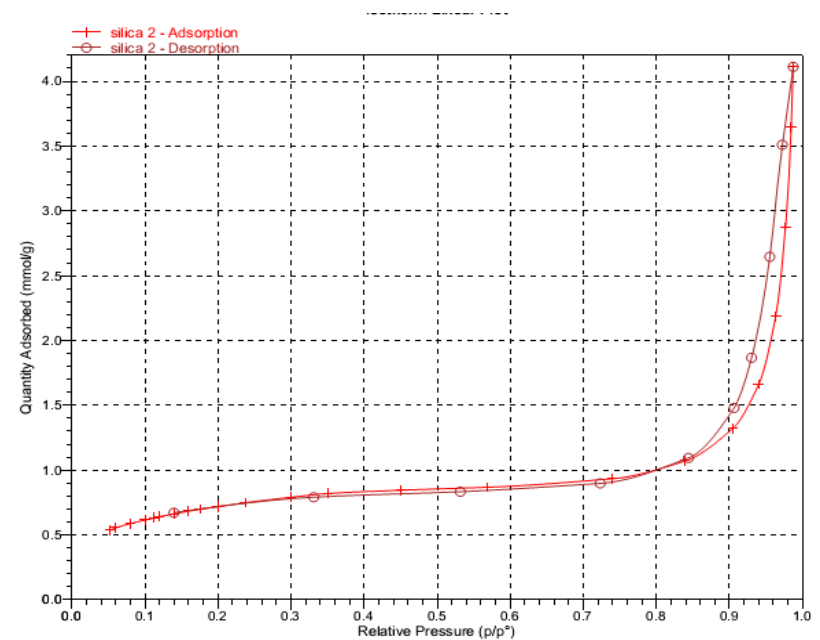

Figure 9: $\mathrm{N}_{2}$ adsorption- desorption isotherm for $\mathrm{Z}$ sample.

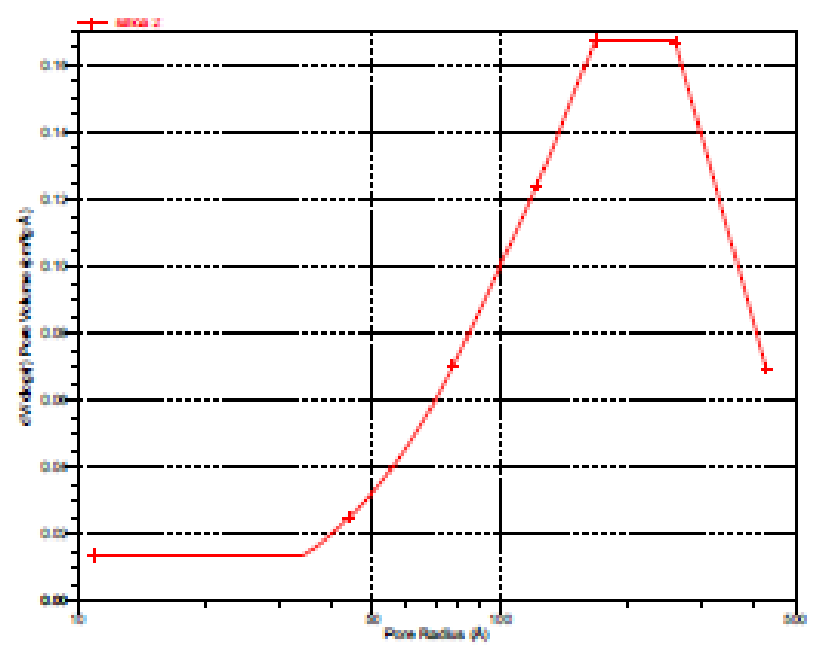

Figure 10: The PZD for $Z$ sample

The $\mathrm{N}_{2}$ adsorption - desorption isotherm for $\mathrm{Z}$ sample (Fig. 9) shows that it can be considered type IV according to the common classification of adsorption isotherms. The hysteresis loops observed are typical for mesoporous materials and resemble the loops of type $\mathrm{H} 1$ according to the IUPAC 


\section{International Journal of Science and Research (IJSR) \\ ISSN (Online): 2319-7064 \\ Index Copernicus Value (2013): 6.14 | Impact Factor (2014): 5.611}

classification which mean that the adsorbent has a regular cylindrical pore without intersecting channels [20].In addition, the PZD result (Fig. 10) confirm the presence of mesoporosity in the samples prepared and have a narrow pore size distribution (from 2 to $50 \mathrm{~nm}$ ).

\subsection{Adsorption behavior}

\subsubsection{Effect of adsorbent dose}

The experiment was conducted for $40 \mathrm{mg} / \mathrm{L}$ concentration of solution with different amounts $(0.1,0.2,0.3,0.4$ and $0.5 \mathrm{~g})$ of MPS adsorbents for $50 \mathrm{ml}$ of surfactant NPE, the maximum surfactant removal was achieved within 90 minute. Figure (12) shows the variation of percentage removal ( $\mathrm{R} \%$ ) with the amount of adsorbent. The result of Figure (12) show that the 0.2 $\mathrm{g}$ dose give the best result with $\mathrm{R} \%$ equal to 72.25 , so all the experiments performed with $0.2 \mathrm{gm}$ amount of MPS adsorbent.

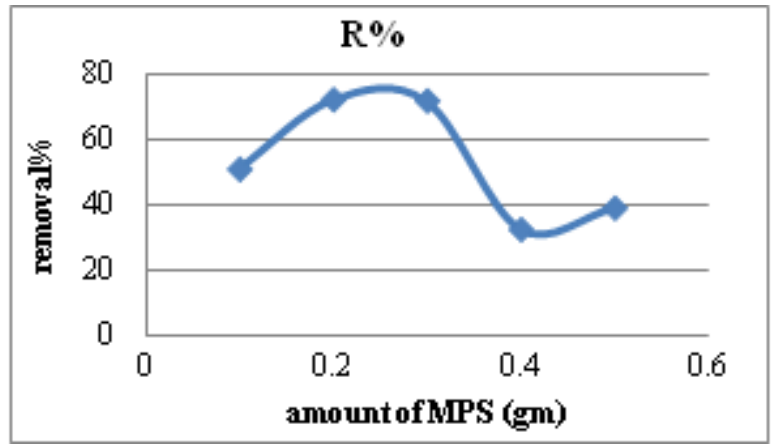

Figure 12: Effect of adsorbent dose on removal of NPE
The effect of contact time on the adsorption of NPE on MPS is illustrated in Figure (13) which shows the gradual increase in adsorption with increasing contact time up to 90 minutes in which a maximum value of adsorption is attained, so all the experiments of adsorption were done at this equilibrium time.

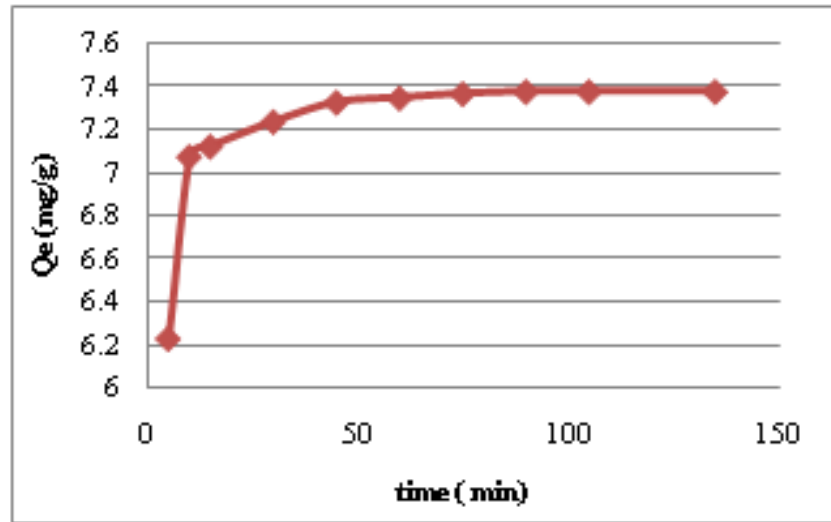

Figure 13: Effect of contact time on removal of NPE

\subsubsection{Adsorption Isotherm}

The adsorption isotherm was constructed using $50 \mathrm{ml}$ of NPE at ten different surfactant concentrations $(5,10,15,20,25$, $30,35,40,45,50 \mathrm{mg} / \mathrm{l})$ with $0.2 \mathrm{~g}$ of MPS at $298,308,318$, and $328 \mathrm{~K}$. The amount of surfactant adsorbed was determined by the equation (1), and the results obtained were listed in Table (1) and given in Figure (14).

\subsubsection{The effect of equilibrium time}

Table 1: The values of $C_{e}$ and $Q_{e}$ for the adsorption of NPEat different temperatures

\begin{tabular}{|c|c|c|c|c|c|c|c|c|}
\hline \multirow{2}{*}{$\begin{array}{c}\mathrm{C}_{0} \\
\mathrm{mg} / \mathrm{L}\end{array}$} & \multicolumn{2}{|c|}{$298 \mathrm{~K}$} & \multicolumn{2}{|c|}{$308 \mathrm{~K}$} & \multicolumn{2}{c|}{$318 \mathrm{~K}$} & \multicolumn{2}{c|}{$328 \mathrm{~K}$} \\
\cline { 2 - 10 } & $\begin{array}{c}\mathrm{C}_{\mathrm{e}} \\
\mathrm{mg} / \mathrm{L}\end{array}$ & $\begin{array}{c}\mathrm{Q}_{\mathrm{e}} \\
\mathrm{mg} / \mathrm{g}\end{array}$ & $\begin{array}{c}\mathrm{C}_{\mathrm{e}} \\
\mathrm{mg} / \mathrm{L}\end{array}$ & $\begin{array}{c}\mathrm{Q}_{\mathrm{e}} \\
\mathrm{mg} / \mathrm{g}\end{array}$ & $\begin{array}{c}\mathrm{C}_{\mathrm{e}} \\
\mathrm{mg} / \mathrm{L}\end{array}$ & $\begin{array}{c}\mathrm{Q}_{\mathrm{e}} \\
\mathrm{mg} / \mathrm{g}\end{array}$ & $\begin{array}{c}\mathrm{C}_{\mathrm{e}} \\
\mathrm{mg} / \mathrm{L}\end{array}$ & $\begin{array}{c}\mathrm{Q}_{\mathrm{e}} \\
\mathrm{mg} / \mathrm{g}\end{array}$ \\
\hline 5 & 1.5 & 0.87 & 2.6 & 0.6 & 2.8 & 0.55 & 3.1 & 0.4 \\
\hline 10 & 2.94 & 1.76 & 6.1 & 0.9 & 5.07 & 1.23 & 6.8 & 0.8 \\
\hline 15 & 3.7 & 2.82 & 10.4 & 1.15 & 10.36 & 1.16 & 11.26 & 0.935 \\
\hline 20 & 4.33 & 3.91 & 13.7 & 1.57 & 12.64 & 1.83 & 16 & 1 \\
\hline 25 & 7.8 & 4.3 & 16.4 & 2.15 & 16.7 & 2.07 & 19.48 & 1.38 \\
\hline 30 & 9.2 & 5.2 & 19.11 & 2.72 & 18.01 & 2.99 & 21.83 & 2.04 \\
\hline 35 & 10.07 & 6.23 & 23.01 & 2.99 & 23.9 & 2.77 & 25.2 & 2.45 \\
\hline 40 & 10.9 & 7.27 & 28.32 & 2.9 & 26.9 & 3.27 & 28.3 & 2.92 \\
\hline 45 & 11.3 & 8.42 & 30.6 & 3.6 & 28.4 & 4.15 & 30 & 3.75 \\
\hline
\end{tabular}

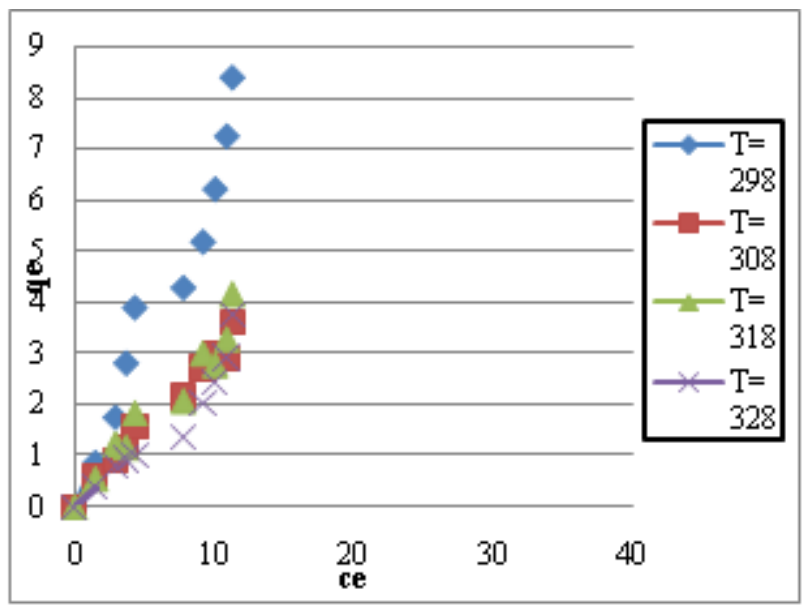

Figure 14: Adsorption isotherm of NPE on MPS at 298, 308, 318, and $328 \mathrm{~K}$. 


\section{International Journal of Science and Research (IJSR) \\ ISSN (Online): 2319-7064 \\ Index Copernicus Value (2013): 6.14 | Impact Factor (2014): 5.611}

As shown in Figure (14) the adsorption isotherm of NPE on MPS was nonlinear and typical S-shape curves. In order to investigate the adsorption isotherm, two isotherms were analyzed: Langmuir and Freundlich. Langmuir represented the following equation [21]

$$
\frac{1}{q_{\mathrm{e}}}=\frac{1}{Q_{0}}+\frac{1}{Q_{0} K_{L} C_{\mathrm{e}}}
$$

Where, $\mathrm{K}_{\mathrm{L}}$ is Langmuir isotherm constant $(\mathrm{L} / \mathrm{mg})$, and $\mathrm{Q}_{\mathrm{o}}$ is maximum monolayer coverage capacity $(\mathrm{mg} / \mathrm{g})$. The linear plots of Langmuir isotherm are shown in Figure (15).

The empirical equation proposed by Freundlich [22] is:

$$
\log \mathrm{q}_{\mathrm{e}}=\log \mathrm{K}_{\mathrm{f}}+1 / \mathrm{n} \log \mathrm{C}_{\mathrm{e}}
$$

Where, $\mathrm{K}_{\mathrm{f}}$ is Freundlich isotherm constant $(\mathrm{mg} / \mathrm{g})$, and $1 / \mathrm{n}$ is dimensionless constant related to the intensity of adsorption, or the heterogeneity factor describes reversible adsorption and is not restricted to the formation of the monolayer. The linear plots of Freundlich isotherm are shown in Figure (16). The parameters obtained from the two models are listed in Table (2).
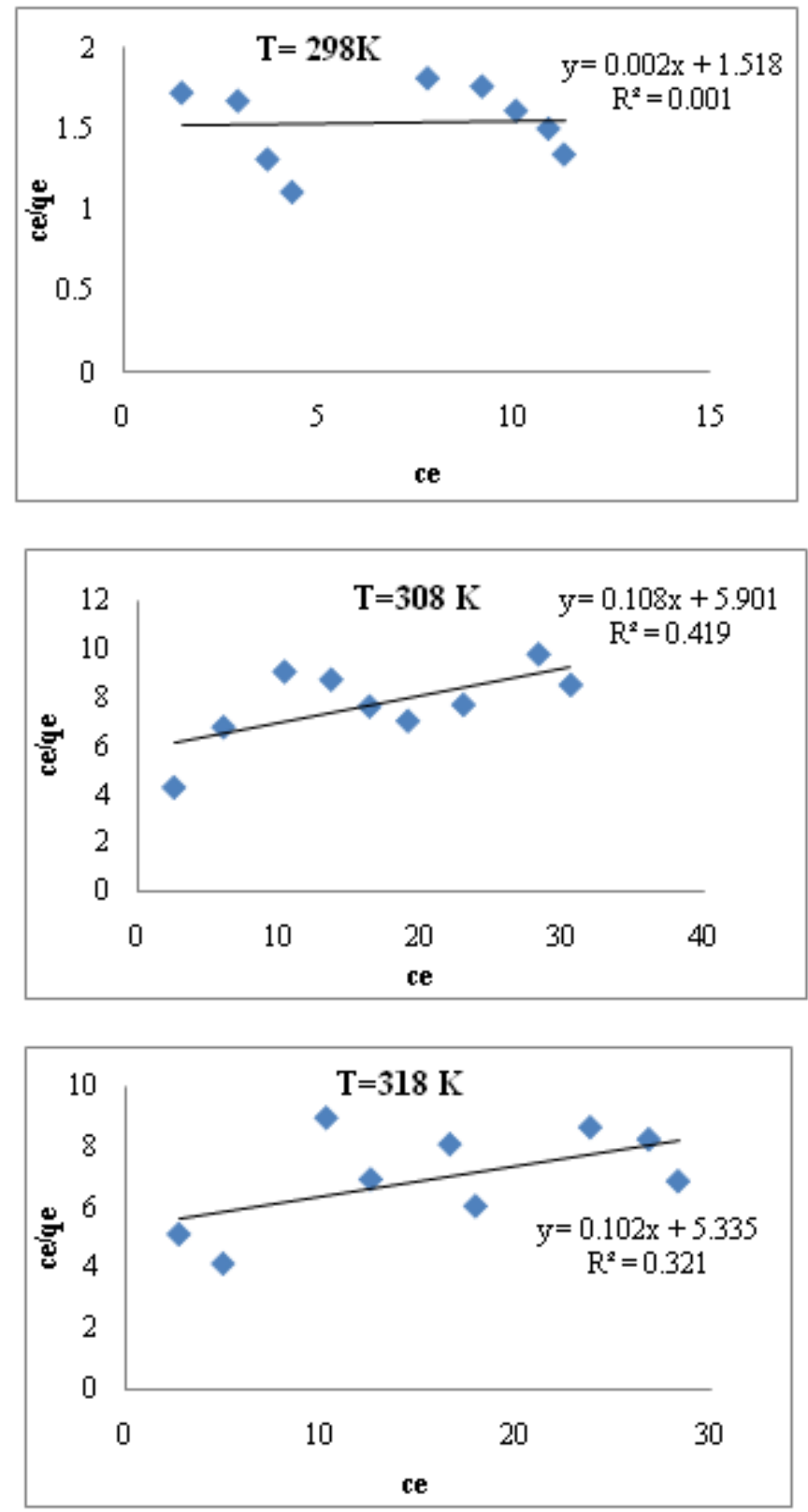

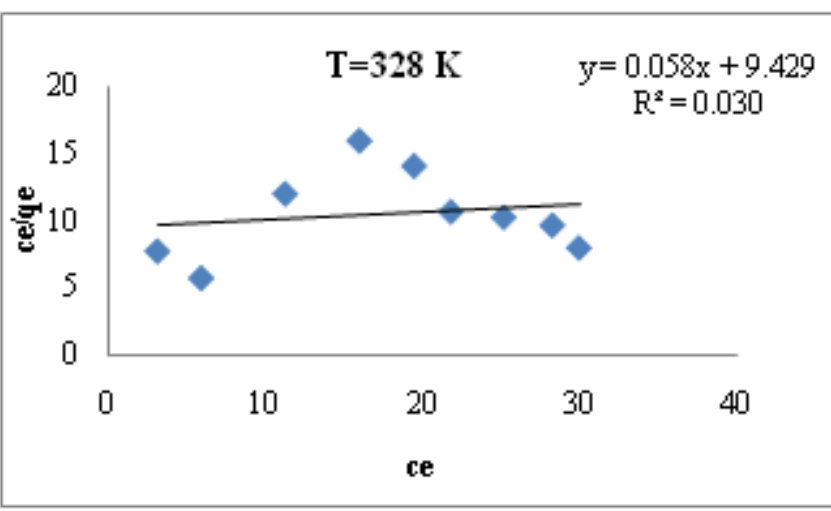

Figure 15: The Linear plots of Langmuir models for adsorption of NPE on MPS at different temperatures.
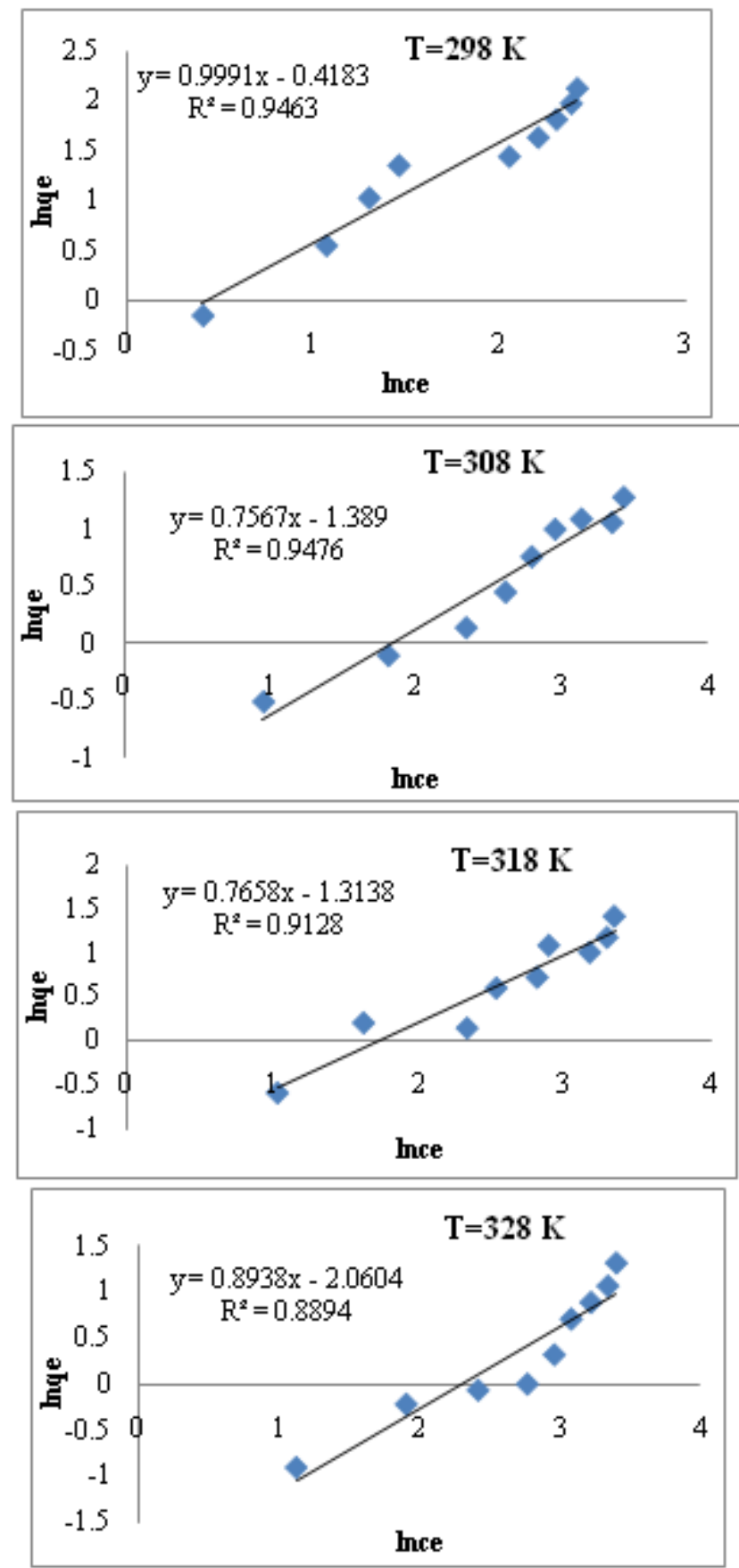

Figure 16: The Linear plot of Freundlich models for adsorption of NPE on MPS at different temperatures. 


\section{International Journal of Science and Research (IJSR) \\ ISSN (Online): 2319-7064 \\ Index Copernicus Value (2013): 6.14 | Impact Factor (2014): 5.611}

Table 2: Langmuir and Freundlich parameters for adsorption on MPS

\begin{tabular}{|c|c|c|c|c|c|}
\hline model & Temp.K & $\mathbf{2 9 8}$ & $\mathbf{3 0 8}$ & $\mathbf{3 1 8}$ & $\mathbf{3 2 8}$ \\
\hline Freundlich & $\mathrm{n}$ & 1.0009 & 1.3058 & 1.3058 & 1.1188 \\
\cline { 2 - 6 } Parameters & $\mathrm{K}_{\mathrm{f}}$ & 1.51 & 4.01 & 3.72 & 7.84 \\
\cline { 2 - 6 } & $\mathrm{R}^{2}$ & 0.9463 & 0.9476 & 0.9128 & 0.8894 \\
\hline \multirow{2}{*}{ Langmuir } & $\mathrm{Q}_{0}$ & 400 & 9.20 & 9.79 & 17.035 \\
\cline { 2 - 6 } & $\mathrm{K}_{\mathrm{L}}$ & 1.5188 & 5.9019 & 5.3358 & 9.4299 \\
\cline { 2 - 6 } & $\mathrm{R}^{2}$ & 0.0016 & 0.4196 & 0.3219 & 0.0307 \\
\hline
\end{tabular}

It can be seen from Table (2), that the correlation coefficient $\left(\mathrm{R}^{2}\right)$ values of Freundlich model are higher than those of Langmuir model, which indicate that the isotherm of the adsorption of NPE surfactants on sample (Z) are best fitted by Freundlich equation and this model may be more appropriate for description of adsorption process. The values of the Freundlich constant $n(1<n<10)$ is an indication that MPS has a high affinity for NPE molecules, and high adsorption intensity.

\subsubsection{Kinetics Study}

The most widely used kinetic models, Lagergren-first-order equation can be expressed as follows [23]:

$$
\ln \left(q_{e}-q_{t}\right)=\ln q_{e}-\left(k_{1} / 2.303\right) t
$$

Where $\mathrm{k}_{1}$ is the rate constant of the pseudo-first order kinetics $\left(\mathrm{min}^{-1}\right) . \mathrm{q}_{\mathrm{e}}$ and $\mathrm{q}_{\mathrm{t}}$ are the amounts of NPE adsorbed on the surface of the adsorbent at equilibrium and at any time $\left(\mathrm{mg} \mathrm{g}^{-1}\right)$ respectively. The $\mathrm{q}_{\mathrm{e}}$ and $\mathrm{k}_{1}$ are calculated from the intercept and the slope of plots of $\log \left(\mathrm{q}_{\mathrm{e}}-\mathrm{q}_{\mathrm{t}}\right)$ vs $\mathrm{t}$ [Fig (17)], respectively, and the result obtained are given in Table (4).

Pseudo-second-order equation modelis given as follows [24]:

$$
\frac{t}{q_{t}}=\frac{1}{k_{2} q_{e}^{2}}+\left(\frac{1}{q_{e}}\right) t
$$

Where $\mathrm{k}_{2}$ is the rate constant of the pseudo-second order kinetics $\left(\mathrm{g} \mathrm{mg}^{-1} \mathrm{~min}^{-1}\right) . \mathrm{k}_{2}$ and $\mathrm{q}_{\mathrm{e}}$ are calculated from the intercept and the slope of plots of $t / q_{t}$ against $t$, Fig (14), respectively.

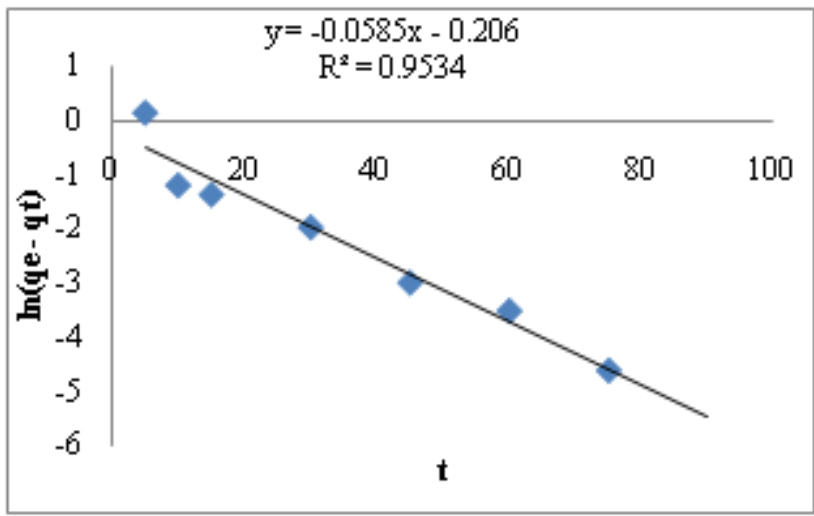

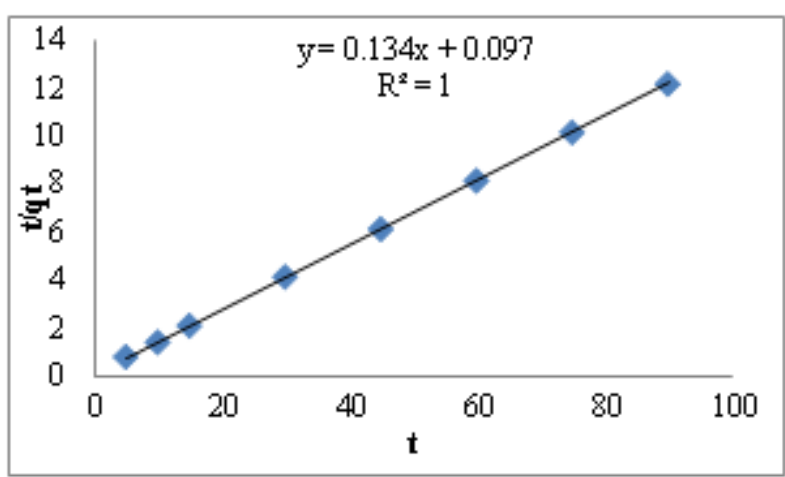

Figure 17: a) pseudo-first order; b) Pseudo-second-order; kinetic plots of NPE on MPS at $298 \mathrm{~K}$.

Intra-particle diffusion model of Weber and Morris [25] can be expressed as follow:

$$
q_{e}=\mathrm{k}_{\mathrm{d}} \mathrm{t}^{1 / 2}+\mathrm{C}
$$

Where, $k_{d}$ is intra-particle diffusion rate constant $\left(\mathrm{mg} \mathrm{g}^{-1}\right.$ $\min ^{-1 / 2}$ ), and $\mathrm{C}$ is intercept. This model reflects that pore diffusion occurs due to the porous nature of adsorbent. The rate constant of the intra-particle diffusion $\left(\mathrm{k}_{\mathrm{d}}\right)$ can be estimated from the slope of the linear plot of the amount of solute adsorbed $\left(\mathrm{q}_{\mathrm{e}}\right)$ against square root of time $\left(\mathrm{t}^{1 / 2}\right)$, Fig (18).These models have been used to research the adsorption kinetic behavior of NPE $(40 \mathrm{mg} / \mathrm{L})$ onto MPS. The best fit model was selected based on the linear regression correlation coefficient values $\left(\mathrm{R}^{2}\right)$. The results of such plots are tabulated in Table (3).

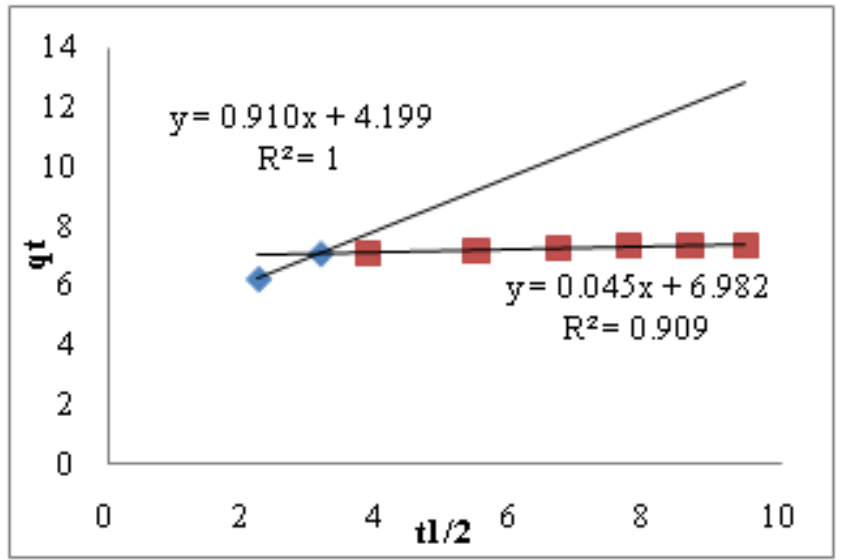

Figure 18: The intra-particle diffusion model of NPE on MPS at $298 \mathrm{~K}$

Table 3: Kinetic parameters for adsorption of NPE on MPS at

\begin{tabular}{|c|c|c|}
\hline \multicolumn{2}{|c}{$298 \mathrm{~K}$} \\
\hline model & parameters & Value \\
\hline \multirow{3}{*}{ Pseudo first order } & $\mathbf{q}_{\mathbf{e}}$ & 0.8138 \\
\cline { 2 - 3 } & $\mathbf{K}_{\mathbf{1}}$ & 0.0585 \\
\cline { 2 - 3 } & $\mathbf{R}^{\mathbf{2}}$ & 0.9534 \\
\hline \multirow{3}{*}{ Pseudo second order } & $\mathbf{q}_{\mathbf{e}}$ & 7.44 \\
\cline { 2 - 3 } & $\mathbf{K}_{\mathbf{2}}$ & 0.184 \\
\cline { 2 - 3 } & $\mathbf{R}^{\mathbf{2}}$ & 1 \\
\hline \multirow{3}{*}{ Diffusion model } & $\mathbf{k}_{\mathbf{D}}$ & 0.0453 \\
\cline { 2 - 3 } & $\mathbf{R}^{\mathbf{2}}$ & 1 \\
\hline
\end{tabular}

From results in Table (3) the correlation coefficient $\left(\mathrm{R}^{2}\right)$ values obtained from pseudo-second order kinetic model was higher than that of pseudo first-order, these indicate that the adsorption perfectly complies with pseudo-second order model. Also, it can be seen from the plot of intra-particle 


\section{International Journal of Science and Research (IJSR) \\ ISSN (Online): 2319-7064 \\ Index Copernicus Value (2013): 6.14 | Impact Factor (2014): 5.611}

diffusion model, the adsorption was controlled by two stages. The first linear portion was a gradual adsorption where intraparticle diffusion was the rate determining factor. The second linear portion was the equilibrium stage due to low concentration of surfactant in the solution phase. As can be seen in the plot, the intraparticlediffusion was not the rate determining factor as the first linear portion of the plot did not pass through the origin [26]-[27].

\section{Conclusions}

From the foregoing results, the following conclusions can be indicating:

1) MPS were prepared by sol-gel process and characterized by FT-IR, AFM, RDX and $\mathrm{N}_{2}$ adsorption- desorption analysis. The analysis of $\mathrm{N}_{2}$ sorption shows that the maximum surface area $\left(54.0398 \mathrm{~m}^{2} / \mathrm{g}\right)$ is obtained for $\mathrm{Z}$ sample.

2) The results of AFM, XRD, and PZD analysis confirm the presence of mesoporosity in the samples prepared and have a narrow pore size distribution (from 2 to $50 \mathrm{~nm}$ ).

3) The adsorption isotherm for NPE adsorption on NPE are well fitted with Freundlich model and shows favorable adsorption.

4) The adsorption kinetics of adsorption process is well described by a pseudo-second order kinetic model and the intraparticle diffusion model suggests that the adsorption process proceeds by surface sorption and intraparticle diffusion.

\section{References}

[1] Sing K.S.W., D.H. Everett, R.A.W. Haul, L. Moscouand, and R.A. Pierotti, "Reporting physisorption data for gas / solid systems with special reference to the determination of surface area and porosity", Pure Appl. Chem., 57: 603-619, 1985.

[2] Atluri, R., Hedin, N. and Garcia-Bennett, E.A., " Hydrothermal phase transformation of bicontinuous cubic mesoporous material AMS-6", Chem Mater, 20, 3857-66, 2008.

[3] Chih-Hsiang, T., " Development and application of multi-functionalized mesoporous silica nanomaterials in intracellular drug delivery and heterogeneous catalysis", Graduate Theses and Dissertations, Iowa State University, Ames, Iowa, 2012.

[4] Marafi, M. and Stanislaus, A., " Spent catalyst waste management: A review: Part I-developments in hydroprocessing catalyst waste reduction and use", Resources, Conserv Recycl, 52, 859-73, 2008.

[5] Aylott, J.W., " Optical nanosensors-an enabling technology for intracellular measurements", Analyst, 128, 309-12, 2003.

[6] Terry Nassivera, Andrew G. Eklund, Christopher C. Landry, " Size-exclusion chromatography of lowmolecular-mass polymers using mesoporous silica", J. Chromatogry A., 973(1-2): 97-101, 2002.

[7] Hao, Y.M., Chen, M. and Hu, Z.B., " Effective removal of $\mathrm{Cu}$ (II) ions from aqueous solution by amino-functionalized magnetic nanoparticles", J. Hazard Mater, 184, 392-9, 2010.
[8] Enobong R. Essien ,Oluyemi A. Olaniyi, Luqman A. Adams, and Rafiu O. Shaibu, "Sol-Gel-Derived Porous Silica: Economic Synthesis and Characterization" .Journal of Minerals and Materials Characterization and Engineering, 11, 976-981, 2012.

[9] Hatem M Alsyouri ,Malyuba A Abu-Daabes, Ayah Alassali and Jerry YS Lin, "Ordered mesoporous silica prepared by quiescent interfacial growth method effects of reaction chemistry", Nanoscale Research Letters, 8:484, 2013.

[10] EdwinE.M , "Characterization of Some Natural and Synthetic Materials With Silicate Structures" , PhD, Lulea University of Technology, 2013.

[11] Xiang Wei-Dong, Yang Yu-Xiang ,Chen Jing ,Wang Zhaolun, and Liu Xiang-Nong, "Preparation of Mesoporous Silica Using Amphoteric Surfactant Potassium and Sodium N-Dodecyl Glycine Template", J. Am. Ceram. Soc., 91(5), 1517-1521, 2008.

[12] FengQ., Yun Hu, XingchenLiua and ChaohaiWeia," The cooperative adsorption properties of cetyl/aminoSBA-15 for 4-nonylphenol", Phys. Chem. Chem. Phys., 17, 19401-19409, 2015.

[13] YanlingZhao ,Jinliang Song , Dong Wu , Tao Tang, and Yuhan Sun, " One-step synthesis of hydrophobic mesoporous silica and its application in nonylphenol adsorption", Journal of Physics and Chemistry of Solids 11, 86, 2015.

[14] Jun Fana, Weiben Yang, and Aimin Li, "Adsorption of phenol, bisphenol A and nonylphenol ethoxylates onto hypercrosslinked and aminated adsorbents", Reactive and Functional Polymers, 71 (10), 994-1000, 2011.

[15] Xiang W. D., Y.-X. Yang, J.L. Zheng, L. Cao, H.J.Ding, X.-N.Liu, " Synthesis of mesoporous silica by cationic surfactant templating in various inorganic acid sources", Materials Science-Poland, 28 (3), 2010.

[16] Kosuge K., Sato T., and Kikukawa N., " Morphological control of rod- and fiberlike SBA-15 type mesoporous silica using water-soluble sodium silicate.Chem Mater", 16, 899-905, 2004.

[17] C. Y. Wang, and X. Li ,Synthesis and Characterization of Organophilic Montmorillonite", Nat. Sci. J. Harbin Normal Univ., 19 (1), 63-5, 2003, (Chinese).

[18] Ryouya, H., Yasuhiro, and Makoto, T., " The syntheses of thin layers of organosilica by the cocondensation of tetraethoxy silane and phenyl triethoxy silane in the presence of cationic surfactant", J. Mater. Sci, 47, 2195-2200, 2012.

[19] Agnieszka K., Waldemar B., and Jacek, G., " The porosity and morphology of mesoporous silica agglomerates", J. Porous Mater, 17, 669-676, 2010.

[20] Rouquerol, J., D. Avnir, C.W. Fairbridge, D.H. Everett and J.H. Haynes, " Physical and biophysical chemistry division commission on colloid and surface chemistry including catalysis", Pure Appl. Chem., 66, 1739-1758, 1994.

[21] Dada, A.O, Olalekan, A.P, Olatunya, A.M., DADA, O, " Langmuir, Freundlich, Temkin and DubininRadushkevich Isotherms Studies of Equilibrium Sorption of $\mathrm{Zn}^{2+}$ onto Phosphoric Acid Modified Rice Husk", OSR Journal of Applied Chemistry, 3 (1), 38 45,2012 


\section{International Journal of Science and Research (IJSR) \\ ISSN (Online): 2319-7064}

Index Copernicus Value (2013): 6.14 | Impact Factor (2014): 5.611

[22] Hutson N.D. and R.T. Yang, "Adsorption" J. Colloid Interf Sci., pp189, 2000.

[23] Lagergren, S.Y., " Zurtheorie der sogenanntena dsorption gelosterstoffe", 1st Edn., Kungliga Svenska Vetenskapsakademiens, Handlingar, pp: 39, 1898.

[24] McKay, G. and Ho, Y.S., " Pseudo-second order model for sorption processes", Process.Biochem., 34, 451465, 1999.

[25] Weber, W.L. and J.C. Morris," Kinetics of adsorption on carbon from solution", J. San. Eng. Div. ASCE, 89:31-39, 1963.

[26] Wan Ngah W.S., M.A.K.M. Hanafiah, S.S. Yong, ," Adsorption of humic acid from aqueous solutions on crosslinked chitosan-epichlorohydrin beads: Kinetics and isotherm studies", Colloids and Surfaces B: Biointerfaces 65, 18-24, 2008.

[27] Sameer H. Kareem and Enaas, " Adsorption of Congo Red, Rhodamine B and Disperse Blue From Aqueous Solution onto Raw Flint Clay", Baghdad Science Journal, 9 (4), 680-688, 2012. 